\title{
A profile of the dentists working in the community dental service in the United Kingdom in 1999
}

\author{
F. A. Blinkhorn, ' A. S. Blinkhorn, ${ }^{2}$ and M. Tickle, ${ }^{3}$
}

\begin{abstract}
Aim To profile the staff in the community dental service (CDS) in terms of qualifications, clinical service provisions and gender. Method Postal questionnaire to all clinical dental service managers in the United Kingdom.

Results The response rate was in the order of $99 \%$. A higher proportion $(67.5 \%)$ of community dental staff are women, but they are more likely $(P<0.001)$ to work part time. There were a higher proportion of men (14.1\%) in the most senior management grade when compared with women $(6.1 \%)$. A postgraduate qualification is relatively common, but men are more likely $(P<0.001)$ to have a higher qualification. The CDS provides a wide range of services centering on clinical care for adults and children, special needs care, epidemiology and health promotion. Most managers tended to have a clinical role. Conclusions Women play an important part in the CDS. They are more likely to work part time, tend to occupy lower positions in the organisation and are less likely to have a postgraduate qualification than men.
\end{abstract}

\footnotetext{
The community dental service (CDS) has been recognised as an 1 important adjunct to the general dental services, ${ }^{1}$ in that it should offer care to those unable to access a general dental practitioner. The CDS is no longer to be seen as a child centred organisation competing with general dental practitioners in the provision of treatment to healthy children. ${ }^{2}$ Key tasks for the CDS are caring for special needs adults and children, helping nervous patients to accept care, undertaking health promotion, screening and epidemiology and acting as a safety net service for those adults and children unable to register with a GDP. A formidable list of tasks given the small number of CDS staff, and the fact that in many areas budgets have contracted. ${ }^{3}$ The CDS has developed rapidly since 1974 when its role was expanded ${ }^{4}$ and the school service side was given less prominence. The CDS has become leaner and many staff are offering care which is both clinically demanding and time consuming. However, with the exception of Scotland ${ }^{5}$ there is little published information on the clinicians providing this expanded service, for example, what are their qualifications, and what are the most popular clinical specialities? Clearly such information is necessary given the fact that the CDS may well be asked to accept more tasks particularly in terms of improving access to dental services. In order to

$1^{*}$ Acting Director of Community Dental Services, Salford Community Healthcare NHS Trust ${ }^{2}$ Professor of Oral Health, University Dental Hospital of Manchester ${ }^{3}$ Consultant in Dental Public Health, Manchester Health Authority

${ }^{*}$ Correspondence to: Dr F A Blinkhorn, Dental Department, Lance Burn Health

Centre, Churchill Way, Salford, Manchester M6 5AU

email:fiona.blinkhorn@man.ac.uk

REFEREED PAPER

Received 28.03.00; Accepted 08.08.00

(C) British Dental Journal 2001; 190: 266-268
}

collect a profile of the CDS, all clinical service managers in the United Kingdom on a list provided by the British Dental Association were contacted and asked to return a simple proforma giving details of their staff.

\section{Methodology}

Discussions were held with five clinical dental service managers to establish 'what information' on the CDS workforce could be collected without recourse to searching through staff files. These managers decided the following could be collected with the minimum of effort:

- Gender

- Full time/sessional

- Grade

- Qualifications

- Primary and secondary clinical duties

- Management responsibilities

Personal information on staff such as surnames and date of birth were not collected and the date of qualification was seen as being too difficult to collect. The information proforma was designed to collect this information and piloted by the five CDS managers. This exercise demonstrated that the proforma could be completed in about 10 minutes. The managers decided the primary and secondary clinical duties and defined those with a management function.

The finalised proforma was sent to all clinical service managers in the UK who were included on a database provided by the British Dental Association. The forms were sent out in August 1999, non responders were contacted again in October 1999 and this was followed up by telephone enquiries in November and December 1999.

Table I Community dental service grades by gender

\begin{tabular}{|c|c|c|c|c|}
\hline Grade & & (\%) & $\begin{array}{l}\text { Female } \\
N \quad(\%)\end{array}$ & $\stackrel{\text { Total }}{N}$ \\
\hline $\begin{array}{l}\text { Dental services } \\
\text { manager or equivalent }\end{array}$ & 73 & $(14.4)$ & $64 \quad(6 . I)$ & 137 \\
\hline $\begin{array}{l}\text { Senior dental officer } \\
\text { or equivalent }\end{array}$ & 209 & $(4 I .2)$ & $318(30.1)$ & 527 \\
\hline $\begin{array}{l}\text { Clinical dental officer } \\
\text { or equivalent }\end{array}$ & 214 & $(42.2)$ & $660(62.5)$ & 874 \\
\hline Consultant & 7 & (I.4) & $\mathrm{I} \quad(0.1)$ & 8 \\
\hline VT or training & I & $(0.2)$ & $4 \quad(0.4)$ & 5 \\
\hline GDP/hybrid & 2 & $(0.4)$ & $5 \quad(0.5)$ & 7 \\
\hline No grade assigned & I & $(0.2)$ & $3(0.3)$ & 4 \\
\hline Total & 507 & $(100.0)$ & $1055(100.0)$ & 1562 \\
\hline
\end{tabular}

9 individuals no information on gender 


\begin{tabular}{|c|c|c|c|c|}
\hline & \multicolumn{3}{|c|}{ Gender } & \multirow[b]{2}{*}{ Tota } \\
\hline & $N^{M a}$ & (\%) & $\begin{array}{l}\text { Female } \\
N \quad(\%)\end{array}$ & \\
\hline Full time & 360 & $(72.1)$ & 410 & 770 \\
\hline Part time & 139 & $(27.9)$ & $629(60.5)$ & 768 \\
\hline Total & 499 & (100.0) & $1039(100.0)$ & \\
\hline
\end{tabular}

Table 3 Summary of postgraduate

\begin{tabular}{lrr}
\multicolumn{3}{l}{ qualifications held by community dental staff } \\
\hline Qualification & $N$ & $(\%)$ \\
\hline Masters degrees & 467 & $(29.7)$ \\
PhD & 21 & $(1.3)$ \\
FDS & 113 & $(7.2)$ \\
D.Orth/M.Orth* & 65 & $(4.1)$ \\
\hline
\end{tabular}

Answers not mutually exclusive $(n=|57|)$

*Orthodontic qualification

The resultant data file was analysed by constructing frequency distributions and by performing cross-tabulations and chi square tests.

\section{Results}

Two hundred and six clinical dental service managers were contacted and only two did not respond, $70.4 \%$ responded to the first letter, $13.1 \%$ to the second request and the remainder were contacted by telephone providing a final response rate of 99.0\%. Data were obtained for 1,571 community dental staff in the United Kingdom of whom 507 (32.5\%) were male and 1,055 (67.5\%) were female. Nine individuals $(0.3 \%)$ did not have their gender specified. The numbers working full time $(n=770 ; 49.0 \%)$ and part time ( $n=768 ; 49.1 \%)$ were nearly the same, although 33 individuals (1.8\%) were not classified.

Table 1 shows the breakdown of the grades in the service by gender. There were differences in the proportions of male and female senior and community dental officers, $41.2 \%$ of males were SDOs and $30.1 \%$ were females. The situation was reversed in the CDO grade with $62.5 \%$ women and $42.2 \%$ men. In the managerial grade there was a higher proportion of males; $14.1 \%$ compared with $6.1 \%$ females, and a marked difference in those with a consultant contract, seven males and one female.

Table 2 compares the working practices in terms of full or part time working of the community staff according to gender. There was a statistically significant difference $(P<0.001)$ recorded in the number of females with part time appointments; 629 females (60.5\%) compared with 139 (27.9\%) males.

Table 3 shows the range of qualifications held by community staff, whilst Table 4 shows qualifications by job designation. It can be seen that a higher qualification is linked to job status. Men were more likely $(P<0.001)$ to have a postgraduate qualification (Table 5) with $50.7 \%$ having an extra qualification compared with $40.7 \%$ of women.

The clinical service managers were also asked to record the primary and secondary clinical services offered by their staff. Information was obtained on 1,561 CDS staff. The majority $(63 \% ; n=984)$ of whom undertook the clinical care of adults and children; whilst $22 \%(n=343)$ offered treatment to special needs groups and the remainder had epidemiology $(9 \% ; n=140)$, health promotion $(5 \%$; $n=78)$ or orthodontics $(1 \% ; n=15)$ as their primary task. A different picture emerged when the second clinical interest was investigated in that the CDS staff offered a wider range of clinical options. Once again special needs was the most popular $(36 \% ; n=562)$ followed by epidemiology $(19 \% ; n=297)$, care of the elderly $(14 \% ; n=218)$, health promotion $(14 \% ; n=218)$ and sedation/GA services $(8 \% ; n=$ 125). In addition staff offered advanced restorative care $(4 \% ; n=62)$, oral surgery $(2 \% ; n=31)$, hospital based care $(2 \% ; n=31)$ and care to the homeless $(1 \% ; n=15)$. Data were available on 1567 individuals and only eight people $(0.5 \%)$ reported a sole managerial function, the majority of staff had more than one task.

\section{Discussion}

The high response rate indicates that the use of a simple data collection tool with limited objectives was a sensible option, and the pilot work certainly proved valuable. However, the level of interest shown by the dental managers indicates that more detailed research in other areas may well be possible using this methodology. The current development of primary care trusts, dental access centres and personal dental service (PDS) pilots and their impact on the CDS could well be investigated using a postal questionnaire methodology.

\begin{tabular}{|c|c|c|c|c|c|c|c|c|}
\hline \multirow[t]{2}{*}{ Grade } & \multicolumn{2}{|c|}{ Masters } & \multicolumn{2}{|c|}{$\mathrm{PhD}$} & \multicolumn{2}{|c|}{ FDS } & \multicolumn{2}{|c|}{ D/M Orth } \\
\hline & $N$ & (\%) & $N$ & (\%) & $N$ & (\%) & $N$ & (\%) \\
\hline $\begin{array}{l}\text { Dental services } \\
\text { manager or equivalent }\end{array}$ & 82 & $(59.9)$ & 4 & (2.9) & 10 & (7.3) & 2 & $(1.5)$ \\
\hline $\begin{array}{l}\text { Senior dental officer } \\
\text { or equivalent }\end{array}$ & 292 & (55.4) & 10 & (1.9) & 80 & $(15.2)$ & 54 & $(I 0.2)$ \\
\hline $\begin{array}{l}\text { Clinical dental officer } \\
\text { or equivalent }\end{array}$ & 89 & $(10.1)$ & 6 & $(0.7)$ & 22 & (2.5) & 5 & $(10.2)$ \\
\hline Consultant & 5 & $(62.5)$ & 1 & $(12.5)$ & 4 & $(50.0)$ & 2 & $(25.0)$ \\
\hline VT or training & 0 & & 0 & & 0 & & 0 & \\
\hline GDP/hybrid & 0 & & 0 & & 0 & & 0 & \\
\hline No grade assigned & I & $(20.0)$ & 0 & & 0 & & 0 & \\
\hline
\end{tabular}

Answers not mutually exclusive ( $n=1568$; 3 missing information) 


\section{RESEARCH \\ community dentistry}

Table 5 A comparison of postgraduate qualification and gender

\begin{tabular}{lccccc}
\hline & \multicolumn{2}{c}{ Male } & \multicolumn{2}{c}{ Female } & Total \\
& $N$ & $(\%)$ & $N$ & $(\%)$ & \\
No PG qualification & 218 & $(49.3)$ & 626 & $(59.3)$ & 844 \\
PG qualification & 289 & $(50.7)$ & 429 & $(40.7)$ & 718 \\
\hline Total & 507 & $(100.0)$ & 1055 & $(100.0)$ & 1562
\end{tabular}

$\chi^{2}=36.9, P<0.001, \mathrm{df}=1$

missing data $=9$

It is clear that members of the CDS are interested in higher qualifications and the employing healthcare trusts have a well-qualified dental workforce. The range of clinical duties offered is very varied, but does centre on the care of vulnerable groups within our society. Failure to recognise this expertise and encourage careers in the CDS could lead to a loss of services to those patients with special needs whose treatment is not really suited to the general dental service.

Prevailing apocryphal views would suggest that the community dental service is dominated by male managers, whilst women predominate in the clinical dental officer grade (CDO). The data presented in Table 1 does show that a higher proportion $(62.5 \%)$ of the female workforce are CDOs and smaller proportions are SDOs $(30.1 \%)$ or managers $(6.1 \%)$ when compared with men. However, when the data presented in Table 1 are recalculated to show the proportional split between men and women who are dental services managers, it can be seen that $53.3 \%$ are men and $46.7 \%$ are women. So the epithet that the CDS is managed by men but run by women is not absolutely true. Nevertheless, the division of management posts is hardly equitable when the reported data (Table 1 ) shows $67.6 \%$ of the clinicians are women. Similar figures were presented by Newton et al., $(2000)^{6}$ and an earlier Scottish paper noted that female dentists made up over half of the Scottish CDS workforce. ${ }^{5}$ A recent paper by Stewart and Drummond also highlights the important role women play in the provision of dental services. ${ }^{7}$

The survey has given some interesting results but clearly it would have been useful to have included year of qualification, as the age profile, particularly by gender, would have provided information on whether more training and recruitment is necessary to maintain the specialist nature of the service. However the questionnaire was designed with advice from dental managers who demanded a minimum data set which did not require delving through personal files. Their suggestions were appropriate as the response rate was nearly $100 \%$, a difficult goal to achieve with any postal survey.

This survey demonstrates the CDS has a highly qualified workforce which has moved into a 'specialist' role providing a complementary service to the GDS. However health service administrators should note that in the current round of reorganisation the CDS contains highly qualified people offering specialist clinical services and care should be taken not to fragment the service leading to clinical isolation and loss of critical mass which any service needs to remain viable.

1. Health Service Management. The future development of the Community Dental Services. Department of Health Circular HC(89)2, London: HMSO, 1991.

2. Primary Care Dental Services. Department of Health Circular HSG(97)4, London: HMSO, 1997.

3. Murray J J, Nunn J H. Trends in the Community Dental Service 1980-1990. Community Dent Health 1993; 10: 335-341.

4. Health Services Development. Community Dental Services. Department of Health Circular HC(78) 14, London: HMSO, 1978.

5. Fyffe H E, Nuttall N M. A profile of dentists working in the general and community dental services in Scotland in 1987. Br Dent J 1989; 166: 411414.

6. Newton J T, Thorogood N, Gibbons D E. A study of the career development of male and female dental practitioners. Br Dent J 2000; 188: 90-94.

7. Stewart F M J, Drummond J R. Women and the world of dentistry. Br Dent J 2000; 188: 7-8. 